Pak. j. sci. ind. res. Ser. B: biol. sci. 2020 63B(3) 179-186

\title{
Assessment of Barley Genotypes Response to Salinity Stress at Early Seedling Growth Stage
}

\author{
Hossein Askari*a, Seyed Kamal Kazemitabarb, Hamid Najafi Zarrinib \\ and Mohammd Hossein Saberic \\ ${ }^{a}$ Department of Agriculture - Jahad, Plant Production Unite, Tabas Golshan, Iran \\ ${ }^{b}$ Department of Plant Science, University of Agricultural Sciences and Natural Resources, Sari, Iran \\ ${ }^{\mathrm{c}}$ Seed and Plant Improvement Research Department, South Khorasan Agricultural \\ and Natural Resources Research and Education Center, Birjand, Iran
}

(received January 30, 2018; revised September 29, 2018; accepted September 30, 2018)

\begin{abstract}
This study was performed to assess several indices for identifying barley genotypes at early growth stage with the best performance in salinity conditions. The effect of salinity treatments was studied through an analysis of the dry matter production, results showed significant differences among genotypes. The majority of used tolerance indices indicated that ESBYTM8910, 4 Shori and MBS8715 were the best barley genotypes showing the highest stress resistance for the greatest $\mathrm{NaCl}$ concentration. It is based on used stability parameters that the genotypes MBS8712 and Jo torsh were the most phenotypically stable. In general, the tolerant genotypes showed the least stability based on mostly of stability parameters.
\end{abstract}

Keywords: barley, stability parameters, tolerance indices

\section{Introduction}

Salinization and soil erosion, which are among the major causes of desertification, have degraded about fifteen percent of the total area of the World (Mariangela and Montemurro, 2015). Drought and salinity as major abiotic stresses are responsible for significant decreased performance in barley on a worldwide scale, and yet under severe stress conditions, barley remains to be an important crop used as feed for animals, malt and human food (Katerji et al., 2006). Establishment stages of the crop such as Germination, Emergence and Early Seedling growth are sensitive to substrate salinity (Saboora et al., 2006). Genotypes assessment under salt stress conditions in early growth stages, such as germination and seedling growth, is widely used and it is known as screening criterion for selection the salt tolerance genotype (Nasser et al., 2001). However, the effectiveness of such techniques varies but controlled environmental conditions can be the main their advantage, therefore these screening techniques are reliable, against the uncertainty of variation in natural conditions in the field (Bernardo et al., 2006). Adverse effects of salinity on seed germination, nodule formation, plant development and crop yield have been reported by several researchers (Muhammad et al., 2006). Selection of barley genotypes under favourable conditions has been reported in several studies by Betran

*Author for correspondence; E-mail: hmss_askari@yahoo.com et al. (2003). Selection by the aim of stress condition has been highly suggested too and the number of researchers have preferred the mid-way and believe in selection under both stress and normal environments (Ashraf et al., 2015). Several selection criteria, such as stress tolerance (TOL) and mean productivity (MP) (Rosielle and Hambling, 1981), stress susceptibility index (SSI) (Fisher and Maurer, 1978), geometric mean productivity (GMP) and stress tolerance index (STI) (Fernandez, 1992) have been proposed as indicators to identify genotypes with better stress tolerance. Giancarla et al. (2012) in evaluating the ability of drought tolerance indices to identify tolerant barley genotypes under laboratory conditions stated these indices may be screened for indirect selection of drought tolerance in the initial stage of the crop growth. As a result, specialization, generalization and phenotypic plasticity are three main methods which have been recognized in plants that are used in dealing with stress. In the first system the genotype is adapted to the specific condition, while in the second method the genotypes have moderate suitability in most environments, and in phenotypic plasticity strategy signals from the environment interact with the genotype and stimulate the production of alternative phenotypes (Fritsche and Borém, 2005).

The development of cultivars, which can be adapted to a wide range of diversified environments (widely adapted) is the final objective of plant breeders. Cultivars 
showing wide adaptation have to be stable for yield in dynamic sense across a range of environments and also their mean performance has to be relatively high (Khalili and Pour-Aboughadareh, 2016). Stability analysis is a good technique for measuring the adaptability of different crop varieties to varying environments and to increase the efficiency of the selection of the superior cultivars by altering their relative productiveness in different environments (Biswas et al., 2012). Environmental variance $\left(\mathrm{Sxi}^{2}\right)$ (Roemer, 1917), Ecovalence $\left(\mathrm{w}_{\mathrm{i}}{ }^{2}\right)$ (Wricke, 1962), Shukla stability variance $\left(\sigma_{i}^{2}\right)$ (Shukla, 1972), Eberhart and Russell Method by Eberhart and Russell (1966) are some of the parametric stability methods that provide a general summary of the response patterns of genotypes to environmental change (Mahtabi et al., 2014). The purpose of this study was to assessment the tolerance and phenotypic stability barley genotypes at early growth stage, based on dry matter production, which provides a quick and simple screening tool for evaluation of genotypic variation in salinity tolerance.

\section{Material and Methods}

The material used for this study comprised 9 barley promising lines and cultivars i.e. STW82153(A), MBS8712(B), ESBYTM8910(C), 4 Shori (D), 5 Shori (E), WB7910(F), Valfajr(G), MBS8715(H) and Jo torsh(I). Germination tests were carried out at 5 levels of electrical conductivities $(\mathrm{ds} / \mathrm{m})(\mathrm{S} 1$ (control) $=4.5$, $\mathrm{S} 2=7.5, \mathrm{~S} 3=10.5, \mathrm{~S} 4=13.5$ and $\mathrm{S} 5=16.5)$. The experiment was arranged in a factorial design with 3 replications on the base of a Completely Randomized Design (CRD). Salinity solutions were prepared by dissolving $\mathrm{NaCl}$ in distilled water at the required concentrations. First, seeds of each genotype were surface sterilized with 5\% sodium hypochlorite solution for $10 \mathrm{~min}$ and then rinsed with sterile distilled water three times, to finally be placed on filter paper into 9 $\mathrm{cm}$ diameter petri dishes ( 25 seeds per Petri dish). In each petri dish, $5 \mathrm{~mL}$ of specific solution was added on alternate days. In order to avoid salt accumulation, filters were replaced in the same interval of time. Seeds were germinated in an incubator at $25^{\circ} \mathrm{C}$ and after 10 days, the effects of salinity levels were studied by sampling on dry weight of plants as biomass production for each treatment. The dry weights were measured by drying the plants at $75^{\circ} \mathrm{C}$ for $48 \mathrm{~h}$, to give a constant weight. Tolerance indices and stability parameters were calculated with this difference that biomass production was replaced with yield. Tolerance indices of SSI (Fischer and Maurer 1978), STI and GMP (Fernandez,
1992), MP and TOL (Rosielle and Hamblin, 1981) were calculated. Then six stability parameters were measured in accordance with Eberhart and Russell,s slop value $\left(b_{i}\right)$ and deviation from regression $\left(\mathrm{S}_{\mathrm{di}}^{2}\right)(1966)$, Roemer, $\mathrm{s}$ environmental variance $\left(\mathrm{S}^{2}{ }_{\mathrm{xi}}\right)(1917)$, Wricke,s ecovalance $\left(\mathrm{W}^{2}\right)(1962)$, Shukla,s stability variance $\left(\sigma_{\mathrm{i}}^{2}\right)$ (1972) and Verma model slop values (Verma et al.,1978). The division of favourable and unfavorable environments was made based on the environmental index that represents the deviation of each environmental mean from the overall mean. Unfavourable environment is that with negative or zero index and favourable environment has positive index, so third level of salinity treatments was determined as middle point of tow environments. Statistical analysis was performed using the R Program. Spearman's Correlation Test was used to determine relationships among variables, and graphs were created using STATISTICA software.

\section{Results and Discussion}

Data of variance analysis (DVA) showed that effectiveness of different levels of salinity and genotypes on seedling growth were significant $(p<0.01)$. Also, there was significant difference amongst the genotype $\times$ salt stress interaction for the biomass production trait $(\mathrm{p}<0.01)$ (Table 1). Overall, $68.4 \%$ of the total sum of squares (SS) was attributed to salinity effects, $14.2 \%$ to genotype and $17.4 \%$ was attributed to genotypes salt interaction effects, respectively. It means that there is a great salinity effect of total variance on genotypes and different genotypes reactions to salinity. Result indicates that biomass production decrease with increasing in salt concentration almost in all barley varieties except the genotype $\mathrm{E}$ that showed unchanged biomass production in second level of salinity and even more amount of that in third level of salt concentrations although their differences were not significant (Table 2). Reverse effects of salinity stress on seedling growth in different crops that was observed in the present study

Table 1. Analysis of variance of biomass production data

\begin{tabular}{lll}
\hline \hline S.O.V & df & MS \\
\hline Treatment & 44 & $68.87^{* *}$ \\
Genotype(G) & 8 & $53.8^{* *}$ \\
Salt(S) & 4 & $518^{* *}$ \\
$\mathrm{G} \times \mathrm{S}$ & 32 & $16.5^{* *}$ \\
Error & 90 & 2.5 \\
\hline \hline
\end{tabular}

$* *=$ significant at the $1 \%$ levels of probability. 
are consistent findings by other researchers (Asfaw, 2011). These results indicate that there is genetic variation among barley genotypes in response to salt stress based on early seedling growth rate. Due to significant statistical difference of genotype $\times$ salt stress interaction, a selection of genotypes with best performance in a level of salinity based on their production in other levels of salinity will not be possible because a genotype might not have the same rank in all levels of salinity stress.
Tolerant genotypes to salinity stress show high values of STI, GMP and MP. In the highest level of salinity, the best results based on stress tolerance indices (STI, TOL, SSI, MP, GMP) belonged to C, H, E and D genotypes (Table 3 ). Correlation coefficient tests of tolerance indices with biomass production under stress (Ys) and non-stress (Yp) conditions showed various results in different levels of salinity (Table 4). Yp and Ys did not have significant positive correlation in all

Table 2. Statistical comparison of means for genotype biomass production (mg/plant) by Duncan's Multiple Range Test $(\alpha=0.01)$

\begin{tabular}{lllllll}
\hline \hline Genotype & \multicolumn{3}{c}{ Salt } & & \\
\cline { 2 - 5 } & $\mathrm{S}_{1}$ & $\mathrm{~S}_{2}$ & $\mathrm{~S}_{3}$ & $\mathrm{~S}_{4}$ & $\mathrm{~S}_{5}$ \\
\hline STW82153 & $27^{\mathrm{ab}}$ & $17.67^{\mathrm{h}-\mathrm{k}}$ & $15.33^{\mathrm{jk}-\mathrm{o}}$ & $11.67^{\mathrm{o}-\mathrm{r}}$ & $12.67^{\mathrm{m}-\mathrm{q}}$ & $16.8^{\mathrm{c}}$ \\
MBS8712 & $24.33^{\mathrm{a}-\mathrm{e}}$ & $19^{\mathrm{g}-\mathrm{j}}$ & $15.67^{\mathrm{jk}-\mathrm{n}}$ & $13.33^{\mathrm{l}-\mathrm{q}}$ & $11.67^{\mathrm{o}-\mathrm{r}}$ & $16.9^{\mathrm{c}}$ \\
ESBYTM8910 & $27^{\mathrm{ab}}$ & $18.33^{\mathrm{g}-\mathrm{k}}$ & $17.33^{\mathrm{h}-\mathrm{k}}$ & $15.67^{\mathrm{jk}-\mathrm{n}}$ & $17^{\mathrm{h}-\mathrm{l}}$ & $19.1^{\mathrm{ab}}$ \\
4 Shori & $22^{\mathrm{c}-\mathrm{g}}$ & $21^{\mathrm{d}-\mathrm{h}}$ & $20.67^{\mathrm{e}-\mathrm{h}}$ & $14.67^{\mathrm{k}-\mathrm{p}}$ & $15.67^{\mathrm{j}-\mathrm{n}}$ & $18.9^{\mathrm{ab}}$ \\
5 Shori & $18.33^{\mathrm{g}-\mathrm{k}}$ & $18.33^{\mathrm{g}-\mathrm{k}}$ & $26^{\mathrm{f}-\mathrm{i}}$ & $12.67^{\mathrm{m}-\mathrm{q}}$ & $11.33^{\mathrm{pqr}}$ & $16.4^{\mathrm{c}}$ \\
WB7910 & $24.67^{\mathrm{a}-\mathrm{d}}$ & $23.33^{\mathrm{b}-\mathrm{f}}$ & $21^{\mathrm{d}-\mathrm{h}}$ & $20^{\mathrm{f}-\mathrm{i}}$ & $11.33^{\mathrm{pqr}}$ & $20.1^{\mathrm{a}}$ \\
Valfajr & $28^{\mathrm{a}}$ & $20.33^{\mathrm{f}-\mathrm{i}}$ & $18.33^{\mathrm{g}-\mathrm{k}}$ & $13^{\mathrm{m}-\mathrm{q}}$ & $12.33^{\mathrm{n}-\mathrm{q}}$ & $18.4^{\mathrm{b}}$ \\
MBS8715 & $25.33^{\mathrm{abc}}$ & $18^{\mathrm{g}-\mathrm{k}}$ & $18.67^{\mathrm{g}-\mathrm{k}}$ & $20^{\mathrm{f}-\mathrm{i}}$ & $16.33^{\mathrm{i}-\mathrm{m}}$ & $19.6^{\mathrm{ab}}$ \\
Jo torsh & $20.67^{\mathrm{e}-\mathrm{h}}$ & $17.67^{\mathrm{h}-\mathrm{k}}$ & $15^{\mathrm{j}^{\mathrm{k}-\mathrm{p}}}$ & $9.67^{\mathrm{qr}}$ & $8.33^{\mathrm{r}}$ & $14.1^{\mathrm{d}}$ \\
& $24.2^{\mathrm{a}}$ & $19.3^{\mathrm{b}}$ & $18.1^{\mathrm{c}}$ & $14.5^{\mathrm{d}}$ & $13^{\mathrm{e}}$ & \\
\hline \hline
\end{tabular}

Value followed by different letter(s) differs significantly.

Table 3. Stress tolerance indices values for studied genotypes

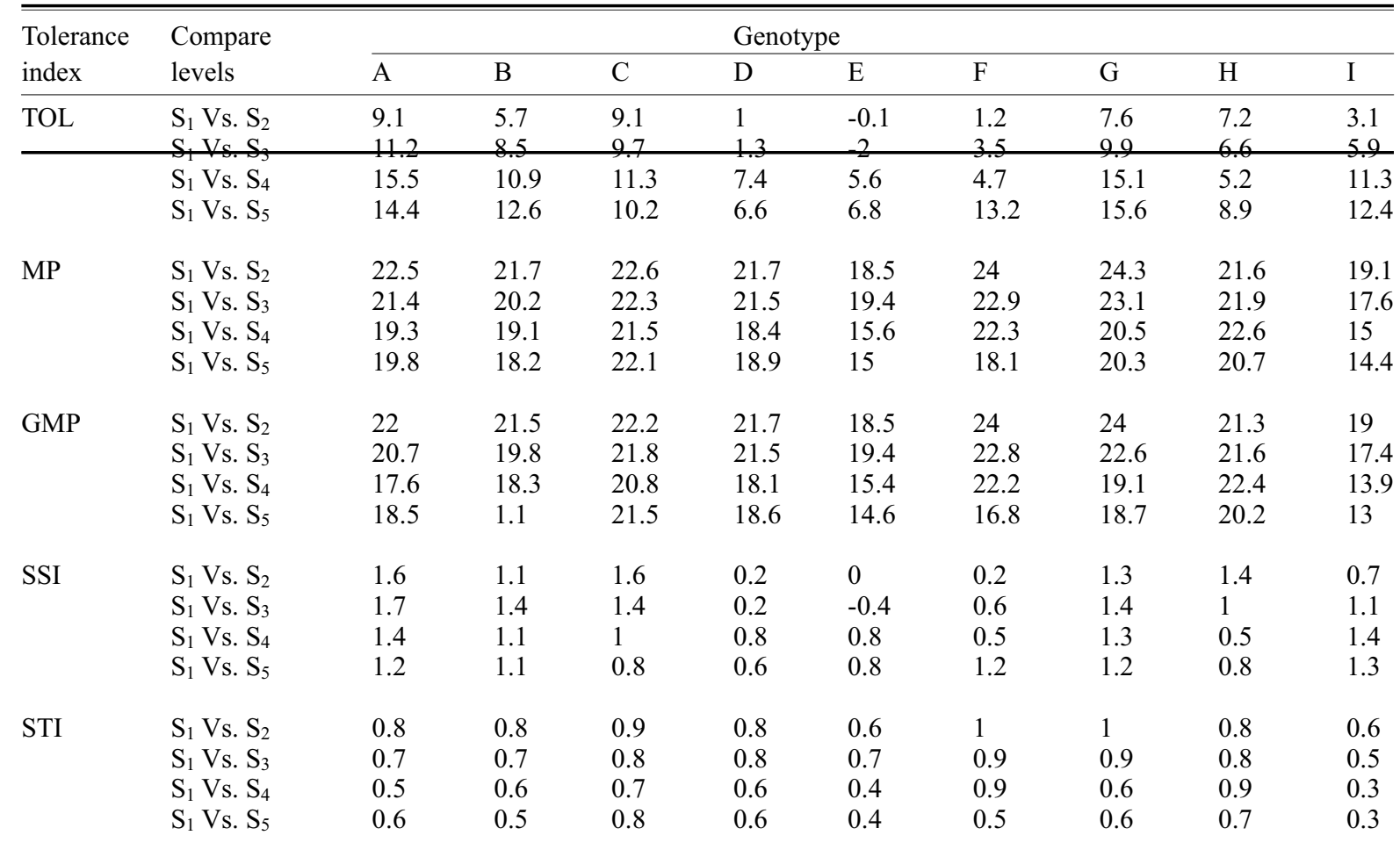


levels of salinity. This reflects that high potential yield under optimal environment does not necessarily result in improved yield in a salinity condition and vice versa. So, in this case selection based on the results of normal conditions as an indirect screening tool will not be efficient. Yp significantly and positively correlated with MP and this case was for STI and Ys.

According to several reports, a genotype with a highly appropriate response to a certain salinity level can not necessarily be considered a tolerant genotype. Instead, a tolerant genotype shows a low yield difference between optimum and stress environments. Fernandez (1992), who studied the yield of genotypes in normal and stress environments, has divided them into four groups, genotypes of group A have high performance in both conditions, genotypes that have a high yield in nonstress environments only belong to group B and genotypes that have high yield in stress conditions are in group $\mathrm{C}$ and genotypes that have low yields in stress and non-stress environments make up group D. As an appropriate measure to separate the first group from the other groups, an analysis of the correlation between responses under stress and non-stress conditions as well as quantitative stress tolerance indices, superior indices and consequently genotypes, was used. Generally, indices having high correlations with plant response in stress and non-stress conditions are introduced as the best ones (Ashraf et al., 2015; Ganjeali et al., 2011). In all of the salinity levels correlation between Yp and Ys was very weak, so selection based on genotype response in one of conditions for the anticipation of its performance in other condition will be powerless. As is shown in Fig. 1a, in spite of SSI high correlation with $\mathrm{Yp}$ and $\mathrm{Ys}$ there is no determined trend for introducing the genotypes with the best reply in both conditions based on SSI. Nevertheless, according to Fig. 1b, STI can be a suitable index for this proposition.

The results of five parametric stability statistics are given in Fig. 2. According to the Eberhart and Russell (1966) model, regression coefficient $\left(b_{i}\right)$ approximating 1.0 coupled with deviation from regression $\left(\mathrm{S}^{2}{ }_{\mathrm{di}}\right)$ of zero indicate average stability. In this case the genotypes with high performance have general adaptability and those which have low mean yield, are adapted to environments poorly. $b_{i}$ values greater than 1 describe genotypes with higher sensitivity to environmental change (below average stability), and greater specificity of adaptability to high yielding conditions. Regression coefficient decreasing below 1 provide a measure of greater resistance to environmental changes (above average stability) and therefore increasing specificity of adaptability to low yielding environments. The

Table 4. Correlation coefficient tests of stress tolerance indices with biomass production under stress (Ys) and control (Yp) $(\alpha=0.05)$

\begin{tabular}{|c|c|c|c|c|c|c|c|c|c|c|c|c|c|c|}
\hline & \multicolumn{7}{|c|}{$\mathrm{S} 1(4.5 \mathrm{ds} / \mathrm{m}) \mathrm{Vs} . \mathrm{S} 2(7.5 \mathrm{ds} / \mathrm{m})$} & \multicolumn{7}{|c|}{$\mathrm{S} 1(4.5 \mathrm{ds} / \mathrm{m}) \mathrm{Vs} . \mathrm{S} 3(10.5 \mathrm{ds} / \mathrm{m})$} \\
\hline & Yp & Ys & TOL & MP & GMP & SSI & STI & Yp & Ys & TOL & MP & GMP & SSI & STI \\
\hline Yp & 1 & & & & & & & 1 & & & & & & \\
\hline Ys & 0.11 & 1 & & & & & & -0.22 & 1 & & & & & \\
\hline TOL & $0.84^{*}$ & -0.46 & 1 & & & & & $0.85^{*}$ & $-0.7^{*}$ & 1 & & & & \\
\hline MP & $0.87^{*}$ & 0.58 & 0.46 & 1 & & & & $0.76^{*}$ & 0.46 & 0.31 & 1 & & & \\
\hline GMP & $0.82 *$ & 0.65 & 0.38 & 1 & 1 & & & $0.67 *$ & 0.57 & 0.19 & $0.99 *$ & 1 & & \\
\hline SSI & $0.8^{*}$ & -0.51 & $0.99 *$ & 0.4 & 0.32 & 1 & & $0.79^{*}$ & $-0.76^{*}$ & $0.99 *$ & 0.22 & 0.1 & 1 & \\
\hline \multirow[t]{3}{*}{ STI } & $0.81 *$ & 0.64 & 0.37 & $0.98 *$ & $0.99 *$ & 0.31 & 1 & 0.56 & $0.67 *$ & 0.05 & $0.95^{*}$ & $0.98 *$ & 0.02 & 1 \\
\hline & \multicolumn{7}{|c|}{$\mathrm{S} 1(4.5 \mathrm{ds} / \mathrm{m})$ Vs. S4 $(13.5 \mathrm{ds} / \mathrm{m})$} & \multicolumn{7}{|c|}{$\mathrm{S} 1(4.5 \mathrm{ds} / \mathrm{m}) \mathrm{Vs} . \mathrm{S} 5(16.5 \mathrm{ds} / \mathrm{m})$} \\
\hline & Yp & Ys & TOL & MP & GMP & SSI & STI & Yp & Ys & TOL & MP & GMP & SSI & STI \\
\hline Yp & 1 & & & & & & & 1 & & & & & & \\
\hline Ys & 0.27 & 1 & & & & & & 0.43 & 1 & & & & & \\
\hline TOL & 0.54 & -0.66 & 1 & & & & & 0.63 & -0.43 & 1 & & & & \\
\hline MP & $0.8^{*}$ & $0.82 *$ & -0.1 & 1 & & & & $0.87 *$ & $0.82 *$ & 0.16 & 1 & & & \\
\hline GMP & 0.64 & $0.91 *$ & -0.3 & $0.98 *$ & 1 & & & $0.77 *$ & $0.91 *$ & 0.02 & $0.98^{*}$ & 1 & & \\
\hline SSI & 0.2 & $-0.9 *$ & $0.92 *$ & -0.47 & -0.63 & 1 & & 0.24 & $-0.76^{*}$ & $0.9^{*}$ & -0.26 & -0.43 & 1 & \\
\hline STI & 0.52 & $0.96^{*}$ & -0.44 & $0.94 *$ & $0.98 *$ & $-0.7^{*}$ & 1 & $0.73 *$ & $0.92 *$ & 0.07 & $0.97 *$ & $0.99 *$ & -0.46 & 1 \\
\hline
\end{tabular}


(a)

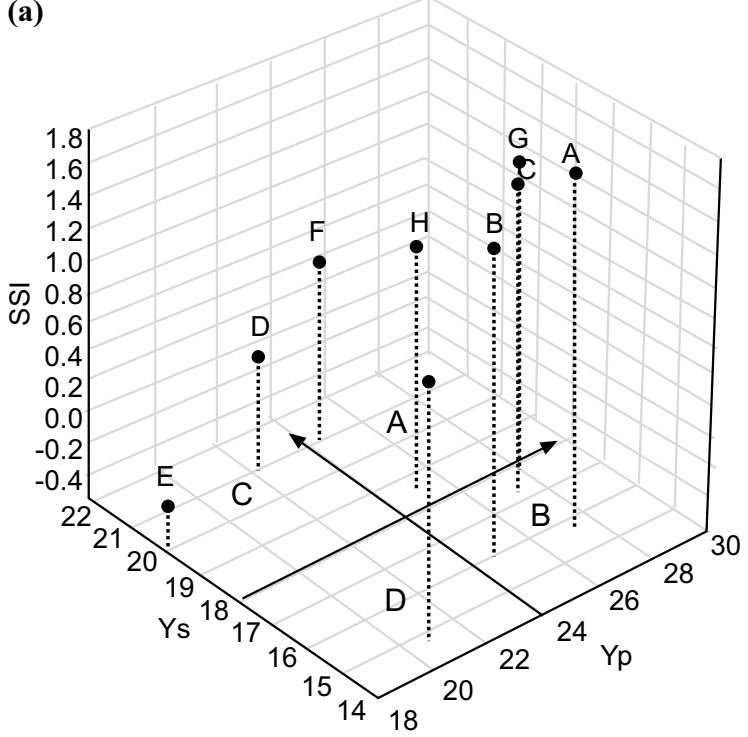

(b)

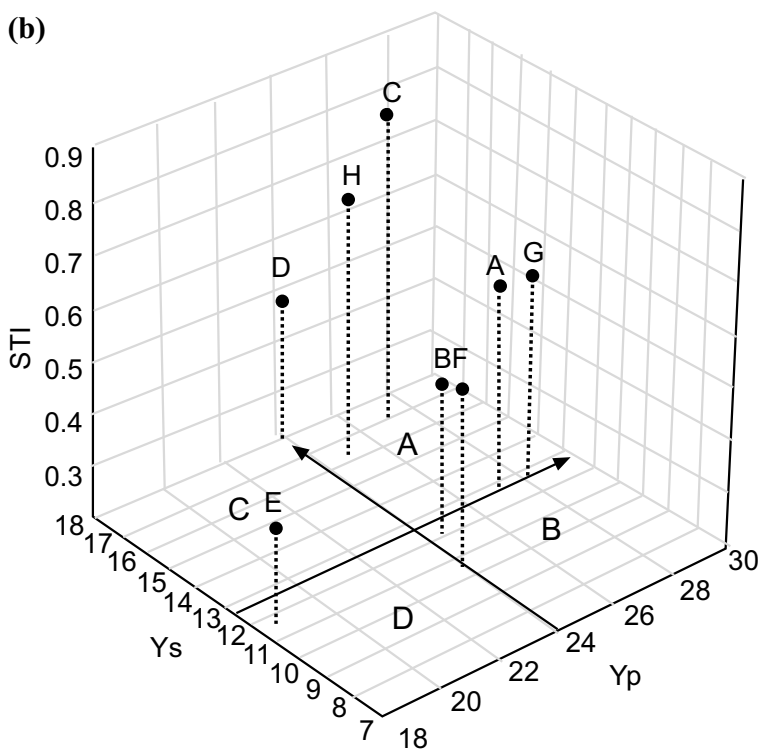

Fig. 1. Dispersion between Yp, Ys and tolerance indices, (a) $\mathrm{S} 1$ (4.5 ds/m) Vs. $\mathrm{S} 3(10.5 \mathrm{ds} / \mathrm{m})$, (b) $\mathrm{S} 1(4.5$ ds/m) Vs. S5(16.5 ds/m). STW 82153(A), MBS8712(B), ESBYTM 8910(C), 4 Shori (D), 5 Shori (E), WB7910(F), Valfajr(G), MBS8715(H) and Jo torsh(I).
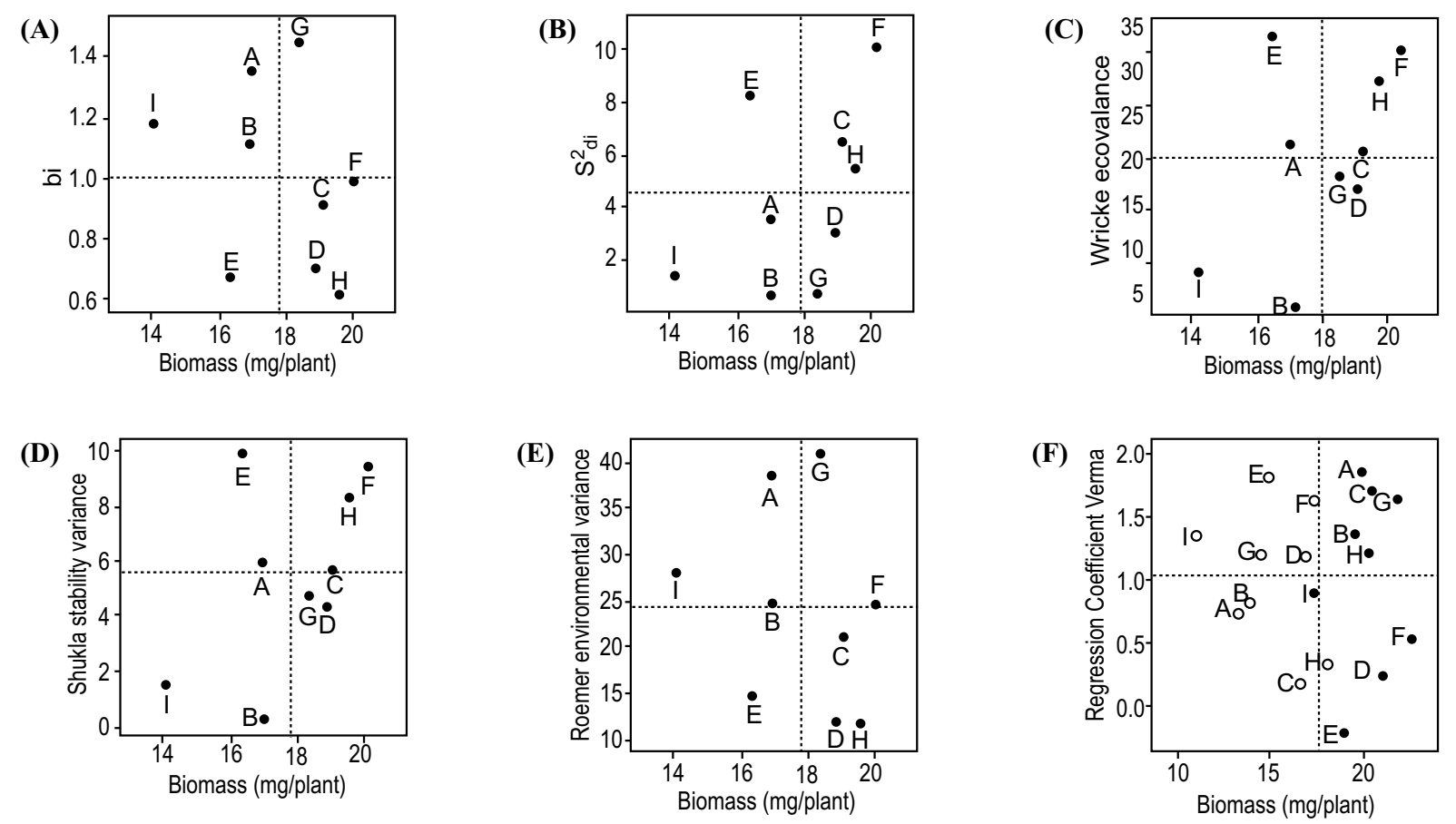

$\circ=$ unfavorable conditions; $\bullet$ = favorable conditions

Fig. 2. Distribution of genotypes on the plot based on stability parameters and biomass production (mg/plant). STW82153(A), MBS8712(B), ESBYTM8910(C), 4 Shori (D), 5 Shori (E), WB7910(F), Valfajr(G), MBS8715(H) and Jo torsh(I). 
genotypes $\mathrm{A}$ and $\mathrm{G}$ had a higher biomass production and a coefficient values greater than one. They are recommended for cultivation under non-stress environments because they are sensitive to changes in conditions and their performance are reduced further by increasing salinity stress. The genotypes with $a b_{i}$ value lower than one were $\mathrm{D}$ and $\mathrm{H}$ that had suitable performance under stress conditions.

According to Wricke,s stability parameter $\left(\mathrm{W}^{2}{ }_{\mathrm{i}}\right)$, genotypes with the smallest ecovalance values are considered stable. The $\left(\mathrm{W}^{2}{ }_{\mathrm{i}}\right)$ was lowest for genotypes $\mathrm{B}$, I and highest for $\mathrm{F}, \mathrm{E}$ and $\mathrm{H}$. The stability variance $\left(\sigma^{2}\right)$ indicated that the genotypes B, I and D had the smallest variance across the salinity levels and were stable, while the genotypes $\mathrm{H}, \mathrm{F}$ and $\mathrm{E}$ had the largest $\left(\sigma_{i}^{2}\right)$ and were unstable. Best performance in favourable environments belonged to $\mathrm{A}, \mathrm{G}$ and $\mathrm{C}$ but with increase in salt concentration $\mathrm{C}$ and $\mathrm{H}$ genotypes were appeared better than others. There are many methods that help plant breeders for the analyses of genotype yield adaptability and stability to identify superior cultivars in the presence of genotype $\times$ environment interaction (GEI). GEI is important source of variation in any crop and the term stability as an adjective for a genotype, shows a relatively constant yield, despite environmental changes. According to this theory, stable genotypes are those that indicate a minimum variance for yield across different environments. This idea of stability may be considered as a biological or static concept of stability (Becker and Leon, 1988). Most breeders and agronomists do not accept this concept of stability and prefer an agronomic or dynamic definition of stability; therefore they prefer genotypes with high performance that have the potential to respond to agronomic inputs or better environment conditions too. In the dynamic definition of stability, the genotype dose not response to environmental conditions equally (Becker and Leon, 1988). Most of the stability methods indicated that the genotype $\mathrm{D}$ was the most phenotypically stable with high mean yield (Fig. 2). Having high performance, low sensitivity to adverse conditions and being capable of responding positively when environmental conditions are improved and the characteristics of a desirable genotype (Ferreira et al., 2006). On this fact the ideal genotype has a regression coefficient smaller than 1 for unfavourable environments and greater 1 for favourable environments. Desirable genotypes have concave pattern for regression linear models and $\mathrm{C}$ and $\mathrm{H}$ genotypes showed such pattern across the levels of salinity (Fig. 3).
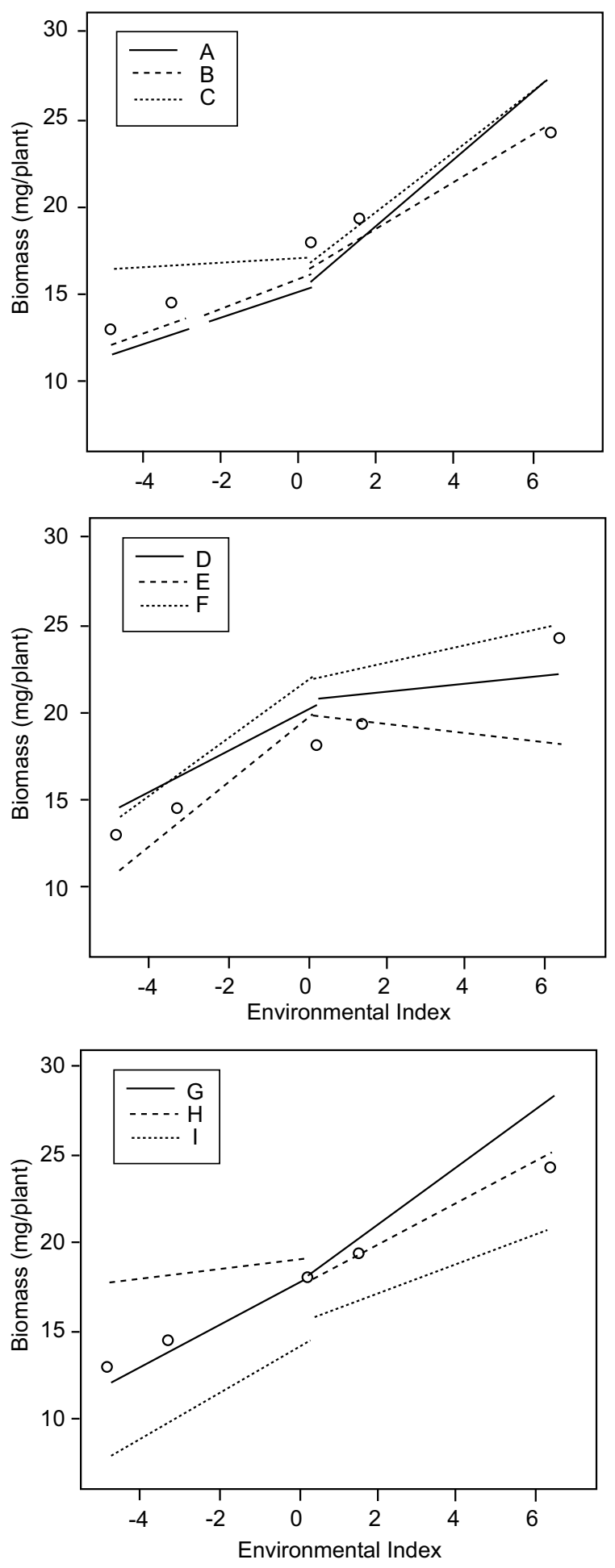

Fig. 3. Performance of barley genotypes across salinity levels based on Verma regression model. STW82153(A), MBS8712(B), ESBYTM8910(C), 4 Shori (D), 5 Shori (E), WB7910(F), Valfajr(G), MBS8715(H) and Jo torsh(I). 
In this study, results determined that genotypes with high STI, MP and GMP values can be considered the most tolerant and desirable genotypes for both growth conditions. On the other hand, it revealed that tolerant genotypes showed the least stability based on mostly of stability parameters. It can be because of variation in their potential for biomass production under different conditions and showed the importance of selection for genotypes performance in both stress and normal environments.

\section{Conclusion}

The results from this study are very useful for the planning of further barley breeding programs. Salt stress significantly affected the performance of barley genotypes. GMP, MP and STI were more suitable indices for selecting barley genotypes tolerant to salt stress. The barley selection using these indices can be useful for identifying a cultivar with desirable establishment under both stress and normal environments. The stability parameters that were used in this study quantified stability of genotypes with respect to performance, stability or both. To exploit the useful effects of genotype $x$ environment interaction and increase the efficiency of genotype selection, both yield and stability should be considered simultaneously. Yet, among all genotypes the WB7910, ESBYTM8910 and MBS8715 showed the best response in the study.

Conflict of Interest. The authors declare no conflict of interest.

\section{References}

Asfaw, K.G. 2011. Effects of salinity on seedling biomass production and relative water content of twenty sorghum (Sorghum biolor L. Moench) accessions. Asian Journal of Agricultural Sciences, 3: 242249.

Ashraf, A., Abdel Shafi, M.A., Gheith, E.M.S., Suleiman, H.S. 2015. Using different statistical procedures for evaluation drought tolerance indices of bread wheat genotypes. Advance in Agriculture and Biology, 4: 19-30.

Becker, H.C., Leon, J. 1988. Stability analysis in plant breeding. Plant Breeding, 101: 1-23.

Bernardo, M., Enrique, T., Jose, L.G. 2006. Effect of $\mathrm{NaCl}$ salinity in the genotypic variation of cowpea (Vigna unguiculata) during early vegetative growth. Scientia Horticulturae, 108: 423-431.
Betran, F.J., Beck, D., Banziger, M., Edmeades, G.O. 2003. Genetic analysis of inbred and hybrid grain yield under stress and non-stress environments in tropical maize. Crop Science, 43: 807-817.

Biswas, P.L., Nath U.K., Ghosal, S., Patwary, A.K. 2012. Genotype-environment interaction and stability analysis of four fine rice varieties. Journal of the Bangladesh Agricultural University, 10: 17.

Eberhart, S.A., Russell, W.A. 1966. Stability parameters for comparing varieties. Crop Science, 6: 36-40.

Fernandez, G.C.J. 1992. Effective selection criteria for assessing stress tolerance. In: Proceedings of the International Symposium on Adaptation of Vegetables and Other Food Crops in Temperature and Water Stress, Kuo, C.G.(ed.) Publication, Tanian, Taiwan.

Ferreira, D.F., Demetrio, C.G.B., Manly, B.F.J., Machado, A.A., Vencovsky, R. 2006. Statistical models in agriculture: biometrical methods for evaluating phenotypic stability in plant breeding. CERNE, 12: 373-388.

Fischer, R.A., Maurer, R. 1978. Drought resistance in spring wheat cultivars. Part-1: grain yield response. Australian Journal of Agricultural Research, 29: 897-912.

Fritsche, R., Borém, A. 2005. Plant breeding for abiotic stress tolerance. Springer Heidelberg New York Dordrecht, London, UK.

Ganjeali, A., Porsa, H., Bagheri, A. 2011. Assessment of Iranian chickpea (Cicer arietinum L.) germplasms for drought tolerance. Agricultural Water Management, 98: 1477-1484.

Giancarla, V., Madosa, E., Sumalan, R., Adriana, C., Cerasela, P. 2012. Evaluation of some indirect indices to identify drought tolerance in barley. Journal of Horticulture, Forestry and Biotechnology, 16: 239-241.

Khalili, M., Pour-Aboughadareh, A. 2016. Parametric and non-parametric measures for evaluating yield stability and adaptability in barley doubled haploid lines. Journal of Agricultural Science and Technology, 18: 789-803.

Katerji, N., Van Hoorn, J.W., Hamdy, A., Mastrorilli, M. 2006. Classification and salt tolerance analysis of barley varieties. Agricultural Water Management, 85: 84-92.

Mahtabi, E., farshadfar, E., Jowkar, M.M. 2014. Stability analysis of yield and yield components in chickpea genotypes. Agricultural Communications, 2: 1-8. 
Mariangela, D., Montemurro, F. 2015. Effectiveness of organic wastes as fertilizer and amendments in saltaffected soils. Agriculture, 5: 221-230.

Muhammad, J., Deog, B.L., Kwang, Y.J., Muhammad, A., Sheong, C., Eui, S.R. 2006. Effect of salt ( $\mathrm{NaCl})$ stress on germination and early seedling growth of four vegetables species. Journal of Central European Agriculture, 2: 273-282.

Nasser, S.H., Nisar, A., Ashraf, M. 2001. Effect of salt stress on germination and seedling growth of barley (Hordeum voulgar L.). Pakistan Journal of Biological Sciences, 4: 359-360.

Roemer, T. 1917. Sind die ertragsreichen sorten ertragssicherer. Mitt. DLG, 32: 87-89.

Rosielli, A.A., Hamblin, J. 1981. Theoretical aspects of selection for yield in stress and non-stress environment. Crop Science, 21: 943-946.

Saboora, A., Kiarostami, K., Behroozbayati, F. 2006. Salinity $(\mathrm{NaCl})$ tolerance of wheat genotypes at germination and early seedling growth. Pakistan Journal of Biological Sciences, 9: 2009-2021.

Shukla, G.K. 1972. Some aspects of partitioning genotype environmental components of variability. Heredity, 29: 237-245.

Verma, M.M., Chahal, G.S., Murty, B.R. 1978. Limitations of conventional regression analysis: a proposed modification. Theoretical and Applied Genetics, 52: 89-91.

Wricke, G. 1962. On a method of understanding the biological diversity in field research. Zeitschrift fur Pflanzenzuchtung. Journal of Plant Breeding, 47: 92-96. 